\title{
Enhanced antitumor effect of combining chemotherapy with Epstein-Barr virus (EBV)-specific cytotoxic T lymphocytes in mice with EBV-related non-Hodgkin's lymphoma
}

\author{
RUI DENG ${ }^{1}$, HAI YI ${ }^{1}$, YI-LAN LIU ${ }^{1}$, FANG-YI FAN ${ }^{1}$, LI FU ${ }^{1}$, YE-CHENG LI ${ }^{1}$, GUO-SHUN LI ${ }^{2}$, \\ SI-HAN LAI ${ }^{1}$, XIAO-JUAN MIAO ${ }^{1}$, YAN-RONG SHUAI ${ }^{1}$, GUANG-CUI HE ${ }^{1}$, \\ YI WANG $^{1}$, YAN ZENG ${ }^{1}$, HAO-PING SUN ${ }^{1}$, LING QIU ${ }^{1}$ and YI SU ${ }^{1}$ \\ ${ }^{1}$ Department of Hematology, Hematopoietic Stem Cell Transplantation and Cell Immunotherapy Center; \\ ${ }^{2}$ Department of Translational Medicine, Experimental Medical Research Center, \\ Cheng Du Military General Hospital of PLA, Chengdu, Sichuan 610083, P.R. China
}

Received June 2, 2015; Accepted August 28, 2015

DOI: $10.3892 / \mathrm{mco} .2015 .646$

\begin{abstract}
Epstein-Barr virus (EBV)-related non-Hodgkin's lymphoma (NHL) represents a major problem in hematological clinical studies due to its drug tolerance and refractoriness. EBV infection is a key factor driving the process of tumor growth. Immune therapy is an important biotherapeutic method of treating cancer, which is attracting increasing attention. We hypothesized that combining conventional chemotherapy with immune therapy in the treatment of EBV-related NHL may achieve better outcomes. First, we successfully cloned large numbers of EBV-specific T cells by immune stimulation ex vivo. Subsequently, the combined therapy was applied in a murine model of human EBV-related NHL. As expected, combined therapy inhibited tumor growth more effectively compared with monotherapy. In addition, we continuously tested the tumor-associated immune microenvironment and observed that the numbers of tumor-infiltrating cytotoxic T lymphocytes (CTLs) and macrophages were elevated following combined therapy. These effects suggest that EBV-specific CTLs may indirectly promote an innate immune reaction in lymphoma by activating tumor-infiltrating macrophage proliferation. Our findings may provide a guide for the prospective treatment of EBV-related NHL.
\end{abstract}

\section{Introduction}

Epstein-Barr virus (EBV) is associated with a number of different types of aggressive non-Hodgkin's lymphoma (NHL).

Correspondence to: Dr Yi Su, Department of Hematology, Hematopoietic Stem Cell Transplantation and Cell Immunotherapy Center, Cheng Du Military General Hospital of PLA, 270 Rongdu Avenue, Chengdu, Sichuan 610083, P.R. China

E-mail: suhang163@hotmail.com

Key words: Epstein-Barr virus, cytotoxic $\mathrm{T}$ cell, lymphoma, chemotherapy, immunotherapy
If B cells infected with EBV express all 9 latent-cycle EBV antigens, the cells become prone to developing a B-cell-derived proliferative disease or tumor. EBV-associated NHLs always exhibit aggressive characteristics, including rapid growth and necrosis. Particularly in cases with EBV-related natural killer (NK)- or T-cell lymphoma, there is a high risk of developing hemophagocytosis syndrome. EBV-positive malignant diseases are associated with the virus latent cycle and the EBV-infected lymphoblastoid cell lines usually exhibit type 3 latency, which renders the cells more susceptible to elimination by EBV-specific T cells (1). Cellular immunotherapy has been developed over the last 20 years to overcome the poor responsiveness to conventional chemotherapy in EBV-associated malignant diseases.

The most frequently used cells in cellular immunotherapy include cytotoxic T lymphocytes (CTLs) and NK cells. CTLs usually exert their effects through recognizing and binding to the antigenic epitopes-MHC-I complex provided by the antigen-presenting cells $(2,3)$. In several types of viral infections, including human immunodeficiency virus (4), EBV (5), cytomegalovirus (6) and hepatitis B and C viruses (7), CTLs play a central role in the defense against viral invasion. In an immune deficiency mouse model of human EBV-transformed B cells, it was demonstrated that EBV-specific CTL treatment effectively prolonged survival (8). According to reported study results, the conventionally used chemotherapy drugs were able to inhibit or promote CTL-mediated tumor cell elimination, depending on the drug category (9). Based on the abovementioned existing theories, we designed this experiment with the aim to investigate the effect of EBV-specific CTL treatment on EBV-related NHL and the potential underlying mechanisms.

The tumor microenvironment has become a research focus in the field of cancer research in recent years. The cells and cytokines in the tumor microenvironment play a crucial role in tumor initiation and progression. This effect is also consistent with lymphoma occurrence. It was previously reported that the genes associated with the tumor microenvironment, cell growth and/or apoptosis and regulation of mitosis were associated with response to treatment and the outcome of 
patients with Hodgkin's lymphoma (10). In addition, the tissue inhibitor of metalloproteinase 1 (TIMP-1) was found to promote EBV-related lymphoma growth, and also inhibit tumor angiogenesis. Therefore, TIMP-1 may be a crucial mediator in EBV-related lymphoma (11). In a mouse model of microenvironment-dependent human diffuse large B-cell lymphoma (DLBCL), bevacizumab exerted a potent antitumor effect by inhibiting tumor vascularization (12). In patients with follicular lymphoma, tumor-associated macrophages were associated with poor prognosis and definitely predicted the outcome (13). Therefore, in the present study, we aimed to determine the post-treatment number of lymphoma-infiltrating macrophages and determine whether adoptive immunotherapy of lymphoma may be associated with tumor microenvironment modulation.

\section{Materials and methods}

Cell lines and reagents. The Farage cell line, which is a human EBV-positive lymphoma cell line, was purchased from American Type Culture Collection (ATCC, Rockville, MD, USA). The cells were traditionally cultured in RPMI-1640 (Sigma-Aldrich Shanghai Trading Co., Ltd., Shanghai, China) supplemented with $10 \%$ fetal bovine serum (Sigma Chemical Co., St. Louis, MO, USA) under conditions of $5 \% \mathrm{CO}_{2}$ in an incubator at $37^{\circ} \mathrm{C}$. Mitomycin $\mathrm{C}$ was purchased from Genia Biology, Beijing, China. Antibodies for flow cytometry were purchased from Becton-Dickinson, San Jose, CA, USA.

EBV-CTL culture and characterization. Monocyte-depleted peripheral blood lymphocytes (PBLs) from EBV-seropositive donors were stimulated with Farage cells incubated overnight at $37^{\circ} \mathrm{C}$. Prior to being added to the PBLs, the Farage cells were treated with mitomycin $\mathrm{C}(10-80 \mu \mathrm{g} / \mathrm{ml})$ for $30 \mathrm{~min}$. Following treatment, the Farage cells were added to the PBLs to co-culture for 4 days, then half of the medium was discarded. The PBLs were collected and re-added to $2 \times 10^{5}$ Farage cells for continuous stimulation. A total of $10 \mathrm{U} / \mathrm{ml}$ human recombinant interleukin (rIL)-2 (Beijing Biodee Biotechnology Co., Ltd., Beijing, China) was added to the PBL medium on day 3; half of the medium was changed every 3 days and the rIL-2 concentration was maintained at $10 \mathrm{U} / \mathrm{ml}$. The stimulation procedure was repeated weekly. The T cells which were able to recognize EBV survived and continued to proliferate, whereas the $\mathrm{T}$ cells which could not recognize EBV gradually underwent apoptosis.mmune phenotype characterization analysis of EBV-CTLs was performed using fluorescein isothiocyanate (FITC)-conjugated antibodies against human CD3 and CD8 (monoclonal rat anti-mouse anti-CD3 and anti-CD8 antibodies, cat. nos. 555275 and 553031, respectively; Becton-Dickinson) by flow cytometry.

EBV-CTL cytotoxicity assay. Target cells $\left(1 \times 10^{6}\right)$ were co-cultured with CTLs of varying concentrations [effector cells:target cells $(\mathrm{E}: \mathrm{T}$ ratio $)=2.5,5.0,10.0$ and 20.0] for $4 \mathrm{~h}$ at $37^{\circ} \mathrm{C}$. Subsequently, MTT assays were performed to evaluate cell viability. A total of $20 \mu \mathrm{l}$ MTT solution $(5 \mathrm{mg} / \mathrm{ml})$ was added to maintain incubation for 1-4 h. The supernatant was carefully discarded and the plates were washed 3 times with phosphate-buffered saline (PBS). Dimethylsulfoxide (150 $\mu \mathrm{l})$ was added to each well and the plates were placed on a shaker for 15-20 min to completely dissolve the formazan crystal violet. Absorbance of Farage cells was tested at $570 \mathrm{~nm}$ using an ELISA reader (Thermo Fisher Scientific Inc., Waltham, MA, USA). The cell death ratio was calculated as follows:

Relative cell death ratio $=(\mathrm{Ae}-\mathrm{Ab}) \times 100 /(\mathrm{Ac}-\mathrm{Ab})$, where Ac, absorbance of control; Ae, absorbance of experimental groups; and Ab, background absorbance.

Adoptive immunotherapy. A total of $20 \mathrm{NOD} / \mathrm{scid}$ nude female mice, aged 5-7 weeks and weighing 15-20 g were purchased from Beijing HFK Bioscience Co., Ltd. (Beijing, China). The mice were housed in sterile cages with unidirectional air flow and supplied with sterile feed and sterile water. The mice were kept according to the institutional guidelines approved by the pla General Hospital of Chengdu Military Region (Sichuan, China) in line with the current regulations and standards of the ministry of Health, Labor and welfare. Logarithmic phase Farage cells $\left(1 \times 10^{6}\right)$ in $100 \mu 1$ serum-free medium were subcutaneously inoculated into the backs of the mice. The mice were randomly divided into four groups (chemotherapy alone, immunotherapy alone, combined therapy and control groups; $n=5$ per group) on the 5th day, when small tumors were palpable. The applied dosage of cyclophosphamide, doxorubicin, vincristine and prednisone (CHOP regimen) was consistent with the existing literature (14). The drugs were infused into the mice according to the study plan. The immunotherapy alone group was administered $20 \times 10^{6} \mathrm{CTLs}$ per mouse per administration through intravenous injection for 5 consecutive days. The control group was injected with serum-free RPMI-1640 medium. All the mice received $2 \times 10^{4}$ IU IL-2 through peritoneal injection daily, for a total of 10 days. The tumor size was measured from the time of the first injection every 2 days. After the 7 th measurement, the mice were sacrificed by cervical dislocation and the tumors were excised and weighed.

Tumor-infiltrating immune cells assay. Fresh tumor tissue was digested with $1 \mathrm{mg} / \mathrm{ml}$ collagenase-1 (Gibco, Ltd, Grand Island, NY, USA) diluted in serum-free RPMI-1640 for 1.5-2 h. The tissue homogenate was centrifuged ( $377 \mathrm{x} \mathrm{g}$ ) for $3 \mathrm{~min}$, the supernatant was removed and the pellet was washed 3 times with PBS. The pellet was resuspended with 5-8 ml PBS ( $\mathrm{pH}=7.4)$ and a cell suspension was formed following filtration. Using a red blood cell counting instrument, single-cell concentration was modulated to $1 \times 10^{5} / 100 \mu 1$. Subsequently, $100 \mu \mathrm{l}$ cell suspension was extracted to incubate with antibodies for flow cytometry. The surface markers CD3-phycoerythrin (PE) with CD8-FITC and CD11b-FITC with F4/80-PE (BD Biosciences Pharmingen, San Jose, CA, USA) were incubated with the cells for $30 \mathrm{~min}$ at $4^{\circ} \mathrm{C}$. Isotype controls were set as the negative controls. The specimens were rewashed with PBS to remove the redundant antibodies. The cells were resuspended in $200 \mu$ l PBS to be evaluated by flow cytometry (Becton-Dickinson). The total cells to be harvested were set to $1 \times 10^{4}$ and the speed of cell collection was controlled at 200-300 cells/sec. The data analysis was completed by FlowJo software, version 7.6 (FlowJo, Ashland, OR, USA). 
A
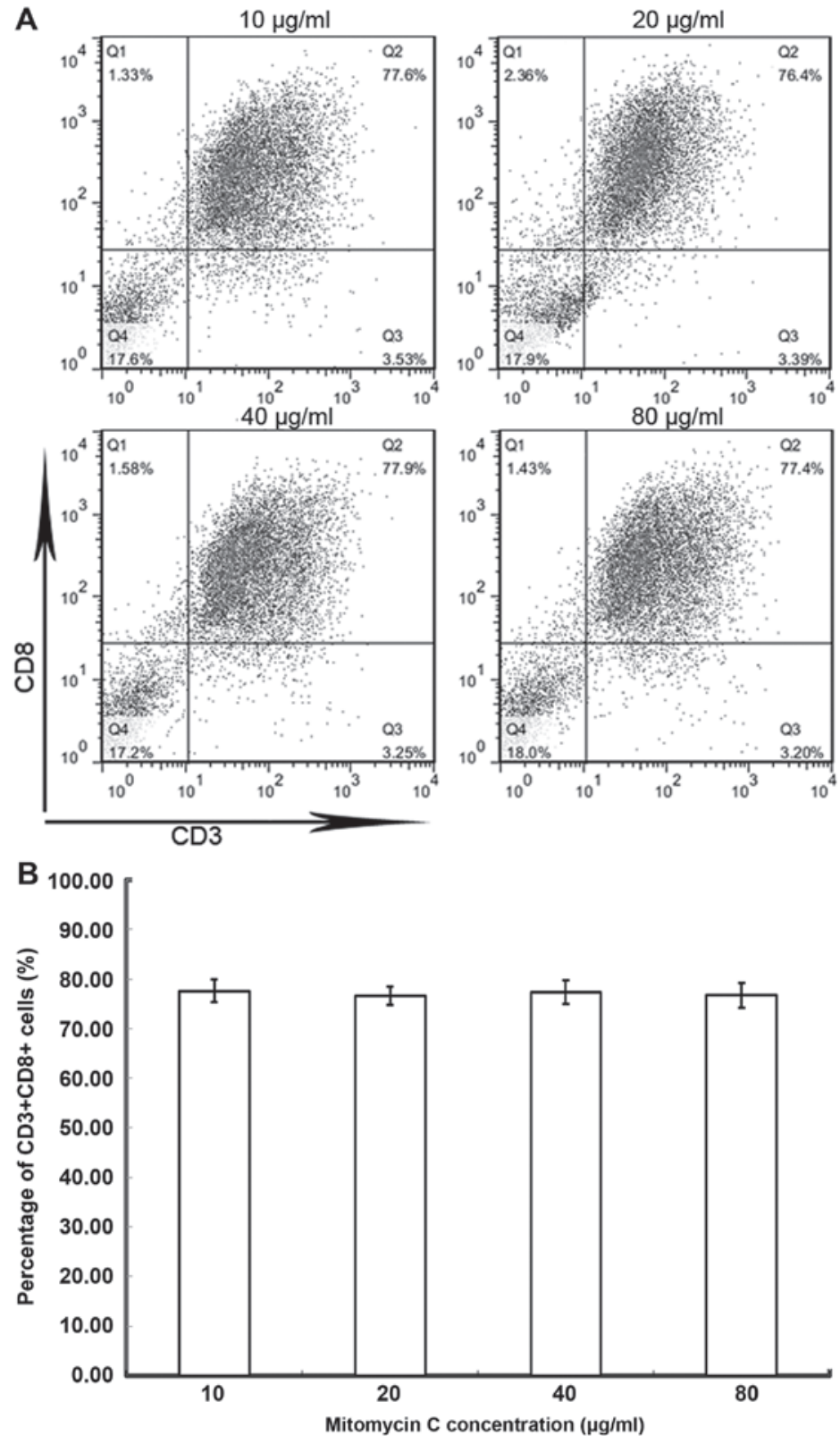

Figure 1. EBV-specific CTL generation. (A) Monocyte-depleted PBLs from EBV-seropositive donors were stimulated by Farage cells pretreated with mitomycin $\mathrm{C}$ and induced to proliferate by rIL-2. Zone Q2 (top right) represents the percentage of $\mathrm{CD} 3^{+} \mathrm{CD} 8^{+}$lymphocytes in the gate. (B) The percentage difference not statistically significant in $\mathrm{CD}^{+} \mathrm{CD}^{+}$lymphocytes that were stimulated by tumor cells treated with mitomycin $\mathrm{C}$ at varying concentrations (10-80 $\mu \mathrm{g} / \mathrm{ml})$. EBV, Epstein-Barr virus; CTL, cytotoxic T lymphocyte; PBL, peripheral blood lymphocyte; rIL-2, recombinant interleukin-2.

Statistical analysis. The data are presented as means \pm standard deviation. The statistical analysis was performed with one-way analysis of variance employing SPSS 16.0 software (SPSS Inc., Chicago, IL, USA). P $<0.05$ was considered to indicate statistically significant differences.

\section{Results}

Cytotoxicity of EBV-CTLs. As CTLs have been recognized as an important tool in cancer immunotherapy, we attempted to generate a significant number of CTLs in vitro by immune stimulation and we cloned out numerous EBV-specific CTLs, which were able to recognize tumor cells containing EBV. Tumor cells treated by mitomycin $\mathrm{C}$ at varying concentrations $(10-80 \mu \mathrm{g} / \mathrm{ml})$ did not result in PBLs proliferating into significantly different numbers of $\mathrm{CD} 8^{+} \mathrm{T}$ cells (Fig. 1). However, all these $\mathrm{CD} 8^{+} \mathrm{T}$ cells displayed specific recognition and cytotoxic abilities. On MTT assays, the specific lysis ratio differed along with the E:T ratio. The results demonstrated that the mean lysis ratio was $9.41,19.45,50.34$ and $55.26 \%$ for an E:T ratio of 2.5:1, 5.0:1, 10.0:1 and 20.0:1, respectively. Compared with the 2.5:1 and 5.0:1 groups, the 10.0:1 and 20.0:1 groups exhibited significant differences in terms of lysis percentage. There were no significant lysis ability differences for the $2.5: 1$ vs. $5.0: 1$ and the $10.0: 1$ vs. $20.0: 1$ groups (Fig. 2).

Antitumor effect of EBV-CTL. To investigate the antitumor effect of EBV-CTLs, we mimicked the human NHL model in $\mathrm{BALB} / \mathrm{c}$ nude mice and applied immune therapy on the mouse 


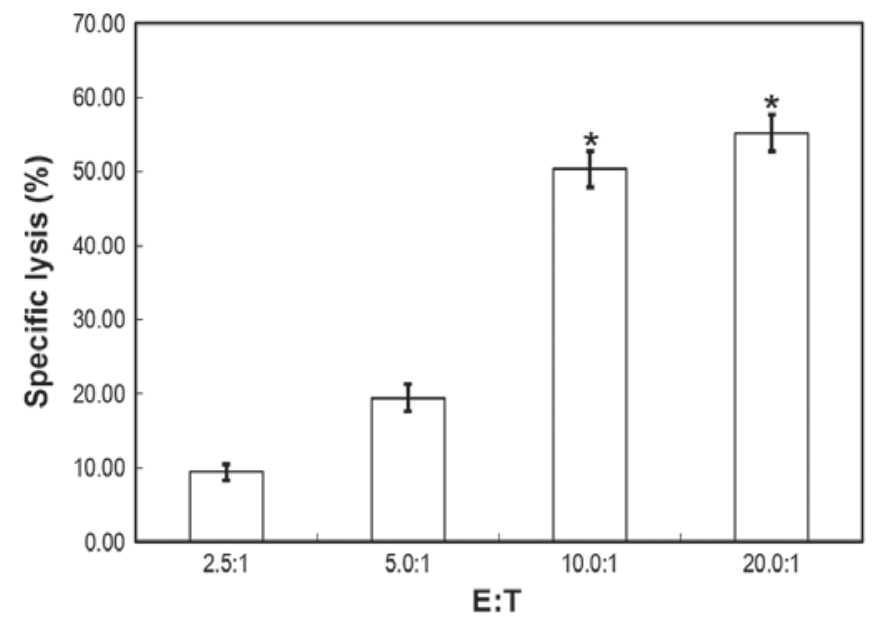

Figure 2. EBV-specific CTL cytotoxicity assay. Target cells $\left(1 \times 10^{6}\right)$ were co-cultured with CTLs of varying concentrations for $4 \mathrm{~h}$ at $37^{\circ} \mathrm{C}$. MTT assays were performed to evaluate cell viability. The specific lysis ratio exhibited a dose-dependent effect. The bars represent means \pm standard deviation. A distinct suppressing effect occurred in the 10:1 and 20:1 groups. ${ }^{*} \mathrm{P}<0.01$ vs. the 2.5:1 and 5.0:1 groups. $\mathrm{n}=5$ tests for each group. EBV, Epstein-Barr virus; CTL, cytotoxic T lymphocyte; E:T, effector cell:target cell ratio.
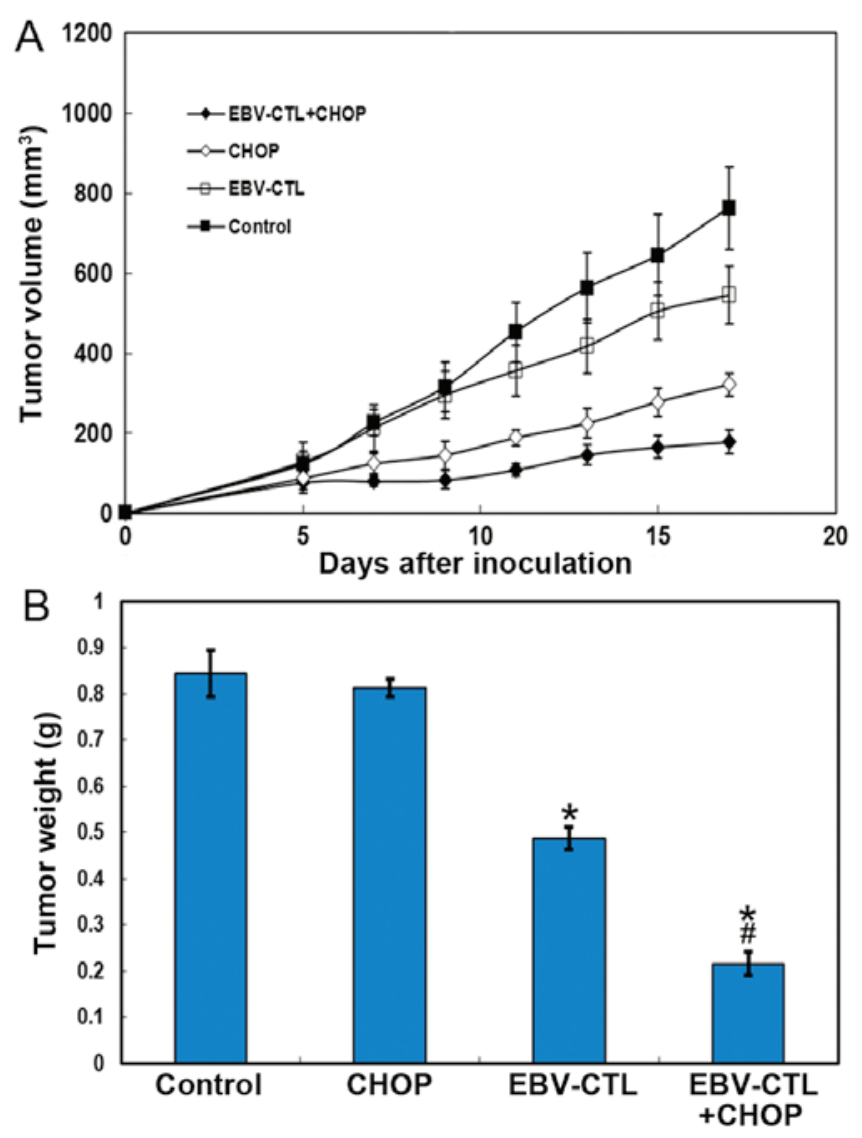

Figure 3. Tumor growth alterations in mice bearing EBV-related non-Hodgkin's lymphoma (NHL). (A) The mice were inoculated with Farage cells and treated with CHOP, EBV-CTL, or both. The animal experiment was repeated twice. The graph shows how combined therapy effectively suppressed mouse EBV-related NHL growth. (B) The tumors were dissected at 20 days after inoculation and weighed. The bars represent means \pm standard deviation. The graph demonstrates that the tumor weight of the experimental groups was decreased compared with the control. ${ }^{*} \mathrm{P}<0.03$ vs. control and EBV-CTL. ${ }^{\text {"}} \mathrm{P}<0.05$ vs. CHOP. $\mathrm{n}=5$ tests for each group. EBV, Epstein-Barr virus; $\mathrm{CHOP}$ cyclophosphamide, doxorubicin, vincristine and prednisone; CTL,cytotoxic T lymphocyte. model. The results demonstrated that the immunotherapy alone group was not superior compared with the chemotherapy alone group. However, the antitumor effect was clearly superior when the mice were treated with combination therapy. From the 3rd day of cell immunotherapy onwards, compared with chemotherapy, statistically significant retardation of tumor growth was observed with combination therapy (Fig. 3A). This retardation effect was enhanced by prolongation of the treatment time. In addition, the tumor weight decreased after the completion of the combined treatment (Fig. 3B).

Immune cell alterations in the tumor microenvironment. Targeting the tumor microenvironment has been proven to be crucial for cancer therapy; however, the effect of immunotherapy on the microenvironment has not been fully elucidated. We hypothesized that a CTL infusion may affect the lymphoma microenvironment and modulate its homeostasis. We observed alterations in the immune cells of the tumor microenvironment with flow cytometry. It was observed that the numbers of tumor-infiltrating CTLs and tumor-infiltrating macrophages (TIMs) varied with the conditions under which the same total cell amounts were collected. The results demonstrated that the mean percentage of $\mathrm{CD} 11 \mathrm{~b}^{+} \mathrm{F} 4 / 80^{+}$cells increased following immunotherapy $(1.96,3.82,0.95$ and $4.33 \%$ in the control, EBV-CTL, CHOP and EBV-CTL+CHOP groups, respectively) (Fig. 4B). Furthermore, the mean percentage of $\mathrm{CD}^{+} \mathrm{CD}^{+}$cells in the treatment groups also increased to varying degrees $(6.32,10.24,6.83$ and $13.65 \%$ in the control, EBV-CTL, CHOP and EBV-CTL+CHOP groups, respectively) (Fig. 4A). The statistical results are presented in Fig. 4C and D.

\section{Discussion}

The majority of EBV-associated tumors respond poorly to conventional or intensive chemotherapy regimens, or exhibit a high relapse rate. The presence of the EBV genome within these tumors promotes the possibility of developing strategies directed against viral targets. Potential intervention strategies include adoptive immunotherapy approaches, interferon and small-molecule compounds targeting different aspects of viral biology (15). To date, the strategy of adoptive transfer of EBV-specificCTLsintolymphoma patients has beeninvestigated universally. It has been proven that EBV-specific CTL lines may be generated from patients with confirmed EBV-positive Hodgkin's disease (16), and such CTL lines may contain clones with specificity for latent membrane protein (LMP) 1 and LMP2 (17). In transplant recipients, EBV-specific T-cell infusions may significantly prolong the survival of patients with EBV-related lymphoproliferative disease (18). In addition, EBV-specific CTLs may eradicate untreated as well as rituximab-resistant lymphoma and EBV-lymphoproliferative disease (19). Adoptive immunotherapy with the cell products has led to in vivo expansion of EBV-CTLs in $80 \%$ of the patients, and a clinical response in $70 \%$ of the patients (20). Consistent with these previous findings, our study also demonstrated the feasibility of generating and infusing EBV-specific CTLs in NHL mouse models. In the present study, we demonstrated that EBV-specific cellular immunity may be effectively detected and expanded in vitro. EBV-specific CTLs were generated 
A
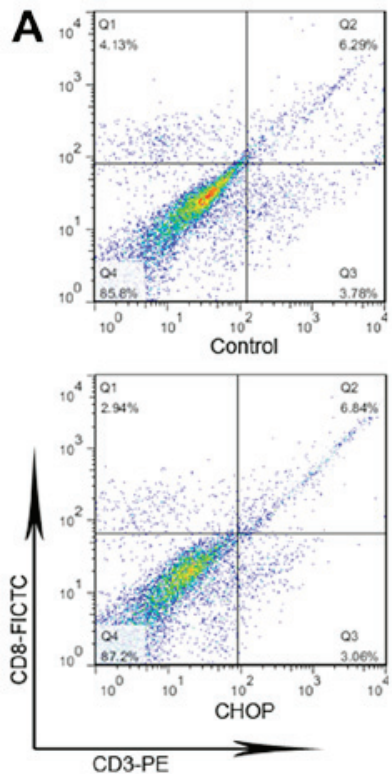

B
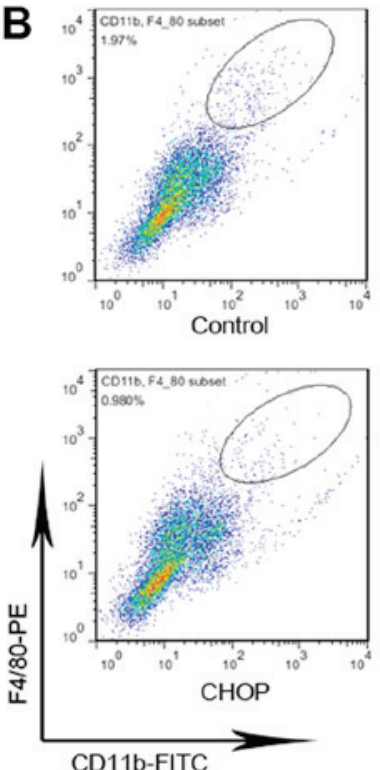
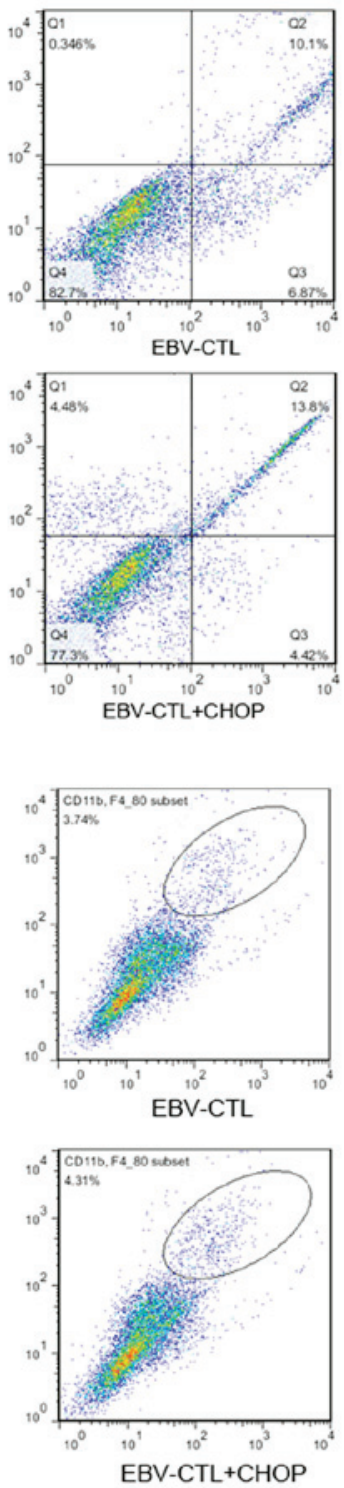
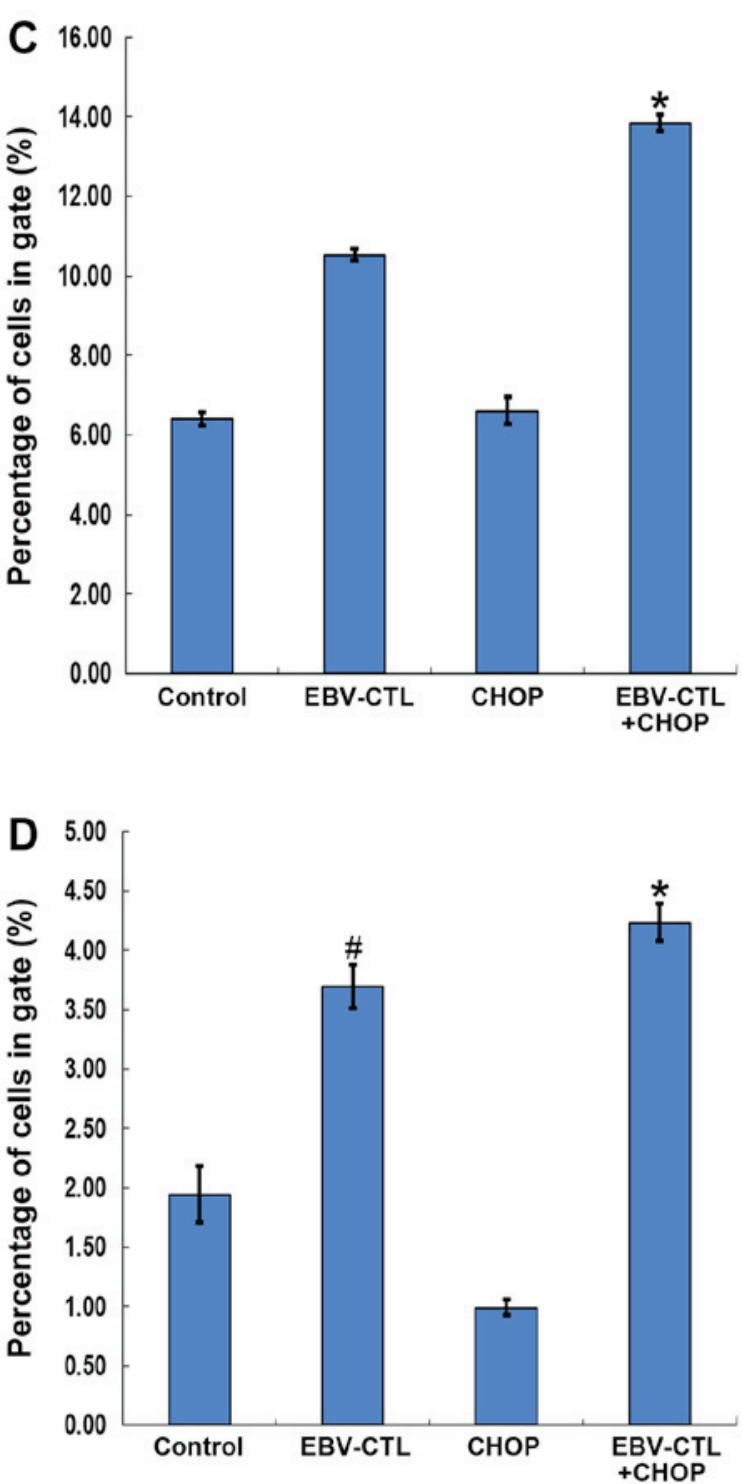

Figure 4. Flow cytometric analysis of tumor-infiltrating immune cells. Tumor-infiltrating cells were digested and analyzed by flow cytometry following treatment. The CTLs were labeled with CD3-PE and CD8-FITC. The macrophages were labeled with CD11b-FITC and F4/80-PE. The relevant isotype control sample was set as negative control. (A) Cells in the right upper quadrant represent the percentage of $\mathrm{CD} 3^{+} \mathrm{CD} 8^{+}$cells. (B) Cells within the circle represent

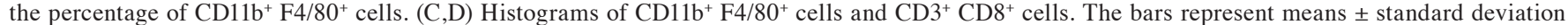
${ }^{*} \mathrm{P}<0.03$ vs. control and CHOP. ${ }^{*} \mathrm{P}<0.05$ control and CHOP. $\mathrm{n}=3$ tests for each group. CTL, cytotoxic T lymphocyte; FITC, fluorescein isothiocyanate; PE, phycoerythrin; CHOP, cyclophosphamide, doxorubicin, vincristine and prednisone.

by tumor antigen stimulation and induced to proliferate by cytokines (Fig. 1). These CTLs possess potent specific lysis ability when abundantly proliferated in vitro (Fig. 2). EBV-specific CTLs may also exert potent antitumor effects in vivo, which achieved a superior treatment response ratio in mice (Fig. 3). However, the cellular monotherapy did not achieve a significantly superior outcome compared with traditional chemotherapy (Fig. 3A), which suggests that cancer treatment, at least in cases with lymphoma, is not be completely replaceable by CTL immunotherapy. However, along with the advances in cancer immunotherapy research, several novel engineering methods for specific CTLs, such as chimeric antigen receptor $\mathrm{T}$ cells, have attracted attention and represent a promising clinical application prospect.
As mentioned above, the tumor microenvironment has been proven to be associated with lymphoma initiation and progression. Cytokines and cells in the tumor microenvironment play crucial roles in modulating the biological behavior of malignant tumors, such as proliferation, differentiation and angiogenesis. In a molecular pathogenesis study on Hodgkin's lymphoma, the expression of a variety of cytokines and chemokines by the tumor cells were considered to be the driving force behind the abnormal immune response. The malignant tumor cells and lymphocyte-predominant $\mathrm{T}$ cells modulate the microenvironment, permitting cells to develop the fully malignant phenotype and evade host immune surveillance (21). The tumor microenvironment was also found to control tumor growth in a human primary effusion lymphoma mouse xenograft 
model (22). High numbers of tumor-infiltrating regulatory $\mathrm{T}$ cells (Tregs) predicted improved survival of follicular lymphoma patients, while a marked reduction in Treg numbers was a predictor of transformation to DLBCL (23). Apart from NHL, an increased number of $\mathrm{CD}^{+} 8^{+}$tumor-associated macrophages was found to be closely associated with shortened survival in patients with classic Hodgkin's lymphoma and provided a new biomarker for risk stratification (24). In the present study, the infused EBV-specific CTLs were found to accumulate in the tumor sites where they exerted their cytotoxic effects (Fig. 4A). Furthermore, the F4/80+ TIMs were also elevated in tumors following immunotherapy (Fig. 4B), which may be attributed to tumor microenvironment alterations. We hypothesized that there are two possible mechanisms underlying TIM upregulation: i) Certain cytokines released by EBV-specific CTLs stimulated and induced peripheral blood PBMCs to differentiate into macrophages and, under the effect of cytokines, these macrophages were recruited to the tumor site; and ii) abundant tumor-associated antigens (TAAs) were released when the EBV-specific CTLs were transfused into the mice, provoking a related innate immune response at the tumor site. However, there are currently no concrete data or proof to support these hypotheses. Therefore, further studies are required and more efforts should be focused on elucidating the role of TIMs in NHL treatment.

In cocnclusion, our present study demonstrated that adoptive transfer of EBV-activated T cells enhanced EBV-related NHL treatment response rate in mice. EBV-specific CTLs may indirectly promote lymphoma immune reaction by activating TIM proliferation, in addition to their direct tumor cytotoxic effect. These results may provide a basis for further research on EBV-related NHL immunotherapy.

\section{Acknowledgements}

This study was supported by the Hospital Management Research Foundation of the PLA General Hospital of Chengdu Military Region (grant no. 2013YG-B045).

\section{References}

1. Heslop HE: Biology and treatment of Epstein-Barr virus-associated non-Hodgkin lymphomas. Hematology Am Soc Hematol Educ Program 2005: 260-266, 2005.

2. Doherty PC and Christensen JP: Accessing complexity: The dynamics of virus-specific T cell responses. Annu Rev Immunol 18: 561-592, 2000.

3. Russell JH and Ley TJ: Lymphocyte-mediated cytotoxicity. Annu Rev Immunol 20: 323-370, 2002.

4. Sun Y, Iglesias E, Samri A, Kamkamidze G, Decoville T, Carcelain G and Autran B: A systematic comparison of methods to measure HIV-1 specific CD8 T cells. J Immunol Methods 272: 23-34, 2003.

5. Subklewe M, Chahroudi A, Schmaljohn A, Kurilla MG, Bhardwaj N and Steinman RM: Induction of Epstein-Barr virus-specific cytotoxic T-lymphocyte responses using dendritic cells pulsed with EBNA-3A peptides or UV-inactivated, recombinant EBNA-3A vaccinia virus. Blood 94: 1372-1381, 1999.

6. Tabi Z, Moutaftsi M and Borysiewicz LK: Human cytomegalovirus pp65 and immediate early 1 antigen-specific HLA class I-restricted cytotoxic $\mathrm{T}$ cell responses induced by cross-presentation of viral antigens. J Immunol 166: 5695-5703, 2001.

7. Rehermann B, Chang K-M, McHutchinson J, Kokka R, Houghton M, Rice CM and Chisari FV: Differential cytotoxic T-lymphocyte responsiveness to the hepatitis $\mathrm{B}$ and $\mathrm{C}$ viruses in chronically infected patients. J Virol 70: 7092-7102, 1996.
8. Nijmeijer BA, Mollevanger $\mathrm{P}$, van Zelderen-Bhola SL, Kluin-Nelemans HC, Willemze R and Falkenburg JH: Monitoring of engraftment and progression of acute lymphoblastic leukemia in individual NOD/SCID mice. Exp Hematol 29: 322-329, 2001

9. Markasz L, Skribek H, Uhlin M, Otvos R, Flaberg E, Eksborg S, Olah E, Stuber G and Szekely L: Effect of frequently used chemotherapeutic drugs on cytotoxic activity of human cytotoxic T-lymphocytes. J Immunother 31: 283-293, 2008.

10. Sánchez-Aguilera A,Montalbán C, dela CuevaP,Sánchez-VerdeL, Morente MM, García-Cosío M, García-Laraña J, Bellas C, Provencio M, Romagosa V, et al; Spanish Hodgkin Lymphoma Study Group: Tumor microenvironment and mitotic checkpoint are key factors in the outcome of classic Hodgkin lymphoma. Blood 108: 662-668, 2006.

11. Guedez L, McMarlin AJ, Kingma DW, Bennett TA, Stetler-Stevenson M and Stetler-Stevenson WG: Tissue inhibitor of metalloproteinase-1 alters the tumorigenicity of Burkitt's lymphoma via divergent effects on tumor growth and angiogenesis. Am J Pathol 158: 1207-1215, 2001.

12. Mori F, Ishida T, Ito A, Sato F, Masaki A, Takino H, Ri M, Kusumoto S, Komatsu H, Ueda R, et al: Potent antitumor effects of bevacizumab in a microenvironment-dependent human lymphoma mouse model. Blood Cancer J 2: e67, 2012.

13. Canioni D, Salles G, Mounier N, Brousse N, Keuppens M, Morchhauser F, Lamy T, Sonet A, Rousselet MC, Foussard C, et al: High numbers of tumor-associated macrophages have an adverse prognostic value that can be circumvented by rituximab in patients with follicular lymphoma enrolled onto the GELA-GOELAMS FL-2000 trial. J Clin Oncol 26: 440-446, 2008.

14. Mohammad RM, Wall NR, Dutcher JA and Al-Katib AM: The addition of bryostatin 1 to cyclophosphamide, doxorubicin, vincristine, and prednisone (CHOP) chemotherapy improves response in a CHOP-resistant human diffuse large cell lymphoma xenograft model. Clin Cancer Res 6: 4950-4956, 2000.

15. Israel BF and Kenney SC: Virally targeted therapies for EBV-associated malignancies. Oncogene 22: 5122-5130, 2003.

16. Frisan T, Sjöberg J, Dolcetti R, Boiocchi M, De Re V, Carbone A, Brautbar C, Battat S, Biberfeld P, Eckman M, et al: Local suppression of Epstein-Barr virus (EBV)-specific cytotoxicity in biopsies of EBV-positive Hodgkin's disease. Blood 86: 1493-1501, 1995.

17. Sing AP, Ambinder RF, Hong DJ, Jensen M, Batten W, Petersdorf E and Greenberg PD: Isolation of Epstein-Barr virus (EBV)-specific cytotoxic T lymphocytes that lyse Reed-Sternberg cells: Implications for immune-mediated therapy of EBV ${ }^{+}$Hodgkin's disease. Blood 89: 1978-1986, 1997.

18. Heslop HE, Slobod KS, Pule MA, Hale GA, Rousseau A, Smith CA, Bollard CM, Liu H, Wu MF, Rochester RJ, et al: Long-term outcome of EBV-specific T-cell infusions to prevent or treat EBV-related lymphoproliferative disease in transplant recipients. Blood 115: 925-935, 2010.

19. Doubrovina E, Oflaz-Sozmen B, Prockop SE, Kernan NA, Abramson S, Teruya-Feldstein J, Hedvat C, Chou JF, Heller G, Barker JN, et al: Adoptive immunotherapy with unselected or EBV-specific $\mathrm{T}$ cells for biopsy-proven $\mathrm{EBV}^{+}$lymphomas after allogeneic hematopoietic cell transplantation. Blood 119: 2644-2656, 2012.

20. Icheva V, Kayser S, Wolff D, Tuve S, Kyzirakos C, Bethge W, Greil J, Albert MH, Schwinger W, Nathrath M, et al: Adoptive transfer of Epstein-Barr virus (EBV) nuclear antigen 1-specific $\mathrm{T}$ cells as treatment for EBV reactivation and lymphoproliferative disorders after allogeneic stem-cell transplantation. J Clin Oncol 31: 39-48, 2013.

21. Steidl C, Connors JM and Gascoyne RD: Molecular pathogenesis of Hodgkin's lymphoma: Increasing evidence of the importance of the microenvironment. J Clin Oncol 29: 1812-1826, 2011.

22. Staudt MR, Kanan Y, Jeong JH, Papin JF, Hines-Boykin R and Dittmer DP: The tumor microenvironment controls primary effusion lymphoma growth in vivo. Cancer Res 64: 4790-4799, 2004.

23. Carreras J, Lopez-Guillermo A, Fox BC, Colomo L, Martinez A, Roncador G, Montserrat E, Campo E and Banham AH: High numbers of tumor-infiltrating FOXP3-positive regulatory T cells are associated with improved overall survival in follicular lymphoma. Blood 108: 2957-2964, 2006.

24. Steidl C, Lee T, Shah SP, Farinha P, Han G, Nayar T, Delaney A, Jones SJ, Iqbal J, Weisenburger DD, et al: Tumor-associated macrophages and survival in classic Hodgkin's lymphoma. N Engl J Med 362: 875-885, 2010. 